\title{
Understanding the Development of Psychopathy:
}

\section{Progress and Challenges}

Viding, E. ${ }^{*} \&$ McCrory, E. ${ }^{1}$

${ }^{1}$ Division of Psychology and Language Sciences, University College London, Gower St, London, WC1E 6BT, UK

*Corresponding author, e.viding@ucl.ac.uk

Total word count: 5796 


\begin{abstract}
Psychopathy is an adult condition that incurs substantial societal and individual costs. Here we review neurocognitive and genetically informative studies that shed light on how and why this condition emerges. Children cannot present with psychopathy. However, the presence of callous-unemotional traits can distinguish a group of children who are at elevated risk of psychopathy in adulthood. These children display diminished empathy and guilt and show attenuated brain activation to distress cues in others. Genetically informative studies indicate that individual differences in callous-unemotional traits show moderate to strong heritability, but that protective environmental factors can counter heritable risk. On the basis of the extant research findings we speculate on what might represent the priorities for research over the next decade. We also consider the clinical implications of these research findings. In particular, we consider the importance of delineating what precisely works for children with callous-unemotional traits (and their parents) and the ways in which intervention and prevention programs may be optimized to improve engagement as well as clinical outcomes.
\end{abstract}




\section{Background}

Psychopathy is a personality disorder characterised by lack of empathy and guilt, shallow affect, manipulation of other people, and severe, premeditated and violent antisocial behaviour (Hare \& Neumann, 2008). Although individuals with criminal psychopathy share many features, including impulsivity, with other antisocial offenders, what really sets them apart is a relative absence of guilt for their actions, little concern for the suffering of their fellow human beings, shallow affiliative bonds and a tendency to not show loyalty unless it is in their own interest (Hare \& Neumann, 2008; Kiehl, 2015). Individuals with psychopathy incur substantial societal costs, both as a direct financial consequence of their offending behaviour and lack of normal participation in working life, but also in terms of the emotional and psychological costs to their victims. Given the serious nature of the disorder, researchers and clinicians are motivated to understand how psychopathy develops and how it might be prevented.

\section{Measuring psychopathy in adults}

Diagnostic manuals such as the Diagnostic and Statistical Manual of Mental Disorders (DSM V) recognize antisocial personality disorder (ASPD), which is characterized by aggression, impulsivity and violation of the rights of others. However, there is no specific diagnostic category of psychopathy. Only a minority of individuals diagnosed with ASPD meet criteria for psychopathy as diagnosed by the Psychopathy Checklist-Revised (Hare, 2003), a standard instrument used in criminal justice settings that measures affective, interpersonal, lifestyle and antisocial features associated with psychopathic personality. Other instruments such as the Triarchic Psychopathy Measure (Patrick, 2010), the Self-Report Psychopathy scale (Paulhus et al, 2016), and the Psychopathic Personality Inventory (Lilienfeld \& Andrews, 1996) are also used to reliably measure psychopathic traits in a 
variety of settings. While there are differences between these measures, all capture aspects of callous presentation, lack of empathy, impulsivity and disinhibition. Some, such as the Triarchic Psychopathy Measure and the Psychopathic Personality Inventory also measure additional domains such as boldness / fearlessness.

\section{Conceptualizing psychopathy within a developmental context}

Can a child present with psychopathy? This remains a complex and controversial question. In our view it is inappropriate (and inaccurate) to label any child as a psychopath. The label of psychopathy is frequently (but not always) used in the context of intractable criminality and violent behaviour. Although the data are clear that comparable personality features and associated neurocognitive indicators can be identified in both adults with psychopathy and children with psychopathic features (Blair et al., 2014; Viding \& McCrory, 2015), we also know that these features and associated behaviours are not fixed during childhood (e.g. Fontaine et al., 2010; Waller et al., 2013). In this light, the negative connotations of a psychopathy label seem overly harsh in reference to children, especially as we know that developmental outcomes are not fixed. This is the reason that we prefer to talk about developmental risk for psychopathy or psychopathic traits/features when we discuss findings relating to children. Our position is also in line with the fact that personality disorder diagnoses more broadly are reserved for adult populations.

However, while psychopathic features, in common with other personality features, may not be fixed across childhood, an established body of research now demonstrates that they are predictive of increased risk for persistent antisocial behaviour and adult psychopathic presentation (Lynam et al., 2007; Viding \& McCrory, 2015). Different measures, such as the Antisocial Process Screening Device (Frick \& Hare, 2001), Youth Psychopathic Traits Inventory (Andershed, Gustafson, Kerr, \& Stattin, 2002), Inventory of 
Callous Unemotional Traits (Essau, Sasagawa, \& Frick, 2006) and Child Problematic Traits Inventory (Colins et al., 2014) reliably capture psychopathic personality traits including callous, unempathetic, interpersonal, and impulsive features. In combination, these traits substantially increase risk of persistent antisocial behaviour in children and youth (Frick et al., 2014, Frogner et al., 2016; Viding \& McCrory, 2015). The diagnostic schemes for Conduct Disorder capture many of the impulsive and interpersonal aspects associated with psychopathic presentation (some of which are shared with other individuals with antisocial behaviour). The recent addition to the American Psychiatric Association Diagnostic and statistical manual of mental disorders $5^{\text {th }}$ edition (DSM 5; American Psychiatric Association, 2013) of a 'limited prosocial emotions' specifier (or callous-unemotional (CU) traits as they have been termed in research contexts) now also provides some coverage of the affective/unempathetic features of psychopathy. In line with the DSM 5 approach, many researchers, ourselves included, have used a measure of CU traits alongside a measure disruptive behaviours (capturing impulsive and interpersonal characteristics) to differentiate a group of children with disruptive behaviours who are at significantly elevated risk for persistent antisocial behaviour / psychopathy, but who differ from other children with disruptive behaviour in their affective presentation.

\section{The Current Review}

In this review, we will provide a short overview of neurocognitive studies that have focused on children with disruptive behaviours and CU traits. Findings from these studies can help us understand the degree to which charting disruptive behaviours together with CU traits identifies a group of children who are comparable to adults who present with psychopathy. We will also discuss genetically informative studies that have focused on psychopathic personality features (often CU traits) or on disruptive behaviours in the presence vs. absence 
of such features. We have chosen to focus this review on the neurocognitive and genetically informative findings for two reasons. First, we think that findings from these two neurobiological areas can inform each other and a possible 'roadmap' for future research efforts that can bring us closer to understanding how psychopathy develops. Second, the extant research findings have a number of clear clinical implications, which we will also discuss.

\section{Findings from neurocognitive studies}

Behaviorally, children with disruptive behaviours and CU traits show a marked lack of empathy or guilt. They often engage in proactive, instrumental aggression, seem impervious to sanctions, and do not appear to exhibit the affiliative needs and goals that characterize typical children (Frick et al., 2014; Viding \& McCrory, 2015). Given this profile, many of the experimental studies on children with disruptive behaviours and CU traits have focused on how they process emotions, whether they empathize with others, how they attend to caregivers, and whether they change their behavior following punishment (for example, see: Bedford et al., 2015; Blair et al., 2014; Dadds et al., 2011; Dadds et al., 2012; Jones et al., 2010; Hodsoll et al, 2014; Kimonis et al., 2008; Martin-Key et al., 2016; Sylvers et al., 2011; Marsh \& Blair, 2008; Schwenck et al., 2012; de Wied et al., 2012; White et al., 2016). The majority of these studies have documented that, compared with typically developing children, those with disruptive behaviours and CU traits are less likely to attend to, react to, and recognize affective stimuli, including distress cues such as fearful and sad expressions of other people; are more likely to show blunted empathy towards others; are less likely to direct attention to the eyes of attachment figures; and adapt less well to changes in reward-punishment contingencies.

Functional magnetic resonance imaging (fMRI) studies of children exhibiting disruptive behaviors and CU traits have largely focused on probing the functioning of brain 
areas implicated in affective/reward processing (see Figure 1) ${ }^{1}$. These studies have indicated a neural activity profile consistent with low emotional responsiveness to others' distress/pain and poor ability to learn from reinforcement information (Blair et al., 2014). Reduced amygdala activity to fearful face in children exhibiting disruptive behaviors with high levels of CU traits relative to typically developing children, children with ADHD, and children exhibiting disruptive behaviors without CU traits has been reported in several studies (for example, see: Jones et al., 2009; Marsh et al., 2008; Viding et al., 2012; Blair et al., 2014) and one study found that the association between $\mathrm{CU}$ traits and proactive aggression is partially mediated by low amygdala reactivity to fearful faces (Lozier et al., 2014). Cohn and colleagues studied fear conditioning in boys with early offending histories and reported that CU traits were negatively associated with anterior cingulate cortex activity during fear conditioning (Cohn et al., 2013). Using an attention-to-emotion paradigm, White et al., (2012) found atypically low amygdala activation to fear stimuli in children with disruptive behaviors and CU traits under low attentional load conditions; fear stimuli typically elicit amygdala activation in healthy volunteers (White et al., 2012). Furthermore, attentional cueing by eye-gaze of a fearful face does not seem to elicit activation in the dorsal frontoparietal endogenous attention-orienting network in children with disruptive behaviors and high CU traits, although this network is reliably activated in typically developing children under such conditions (White et al., 2012).

Reduced amygdala and insula activity in children with disruptive behaviors and high CU traits are also seen when these children engage in more complex forms of social judgment regarding other people's distress, such as categorization of legal and illegal behaviors in moral judgment tasks (Marsh et al., 2011), making decisions about appropriate

\footnotetext{
${ }^{1}$ For an excellent review of structural brain imaging findings in this area see Rogers \& DeBrito (2016). Here we only review findings from functional neuroimaging studies.
} 
responses to the distress of others (Sebastian et al., 2012), or making decisions about whether to benefit self by harming others (Sakai et al., 2017). Finally, five recent studies of children exhibiting disruptive behaviors and varying levels of CU traits (four involving fMRI, and the other brain event-related potential measurement) have reported atypical neural reactivity to other people's pain (Cheng et al., 2012; Lockwood et al., 2013; Marsh et al., 2013; Michalska et al., 2016; Yoder et al., 2016). Collectively, these studies implicate reduced activity and altered connectivity in children with disruptive behaviors and high levels of CU traits in a network of brain areas known to be associated with empathy for other people's pain in healthy individuals. This network encompasses a number of brain regions including the anterior insula, posterior insula, anterior cingulate cortex, and the amygdala. Importantly, this profile of reduced neural reactivity to expressions of pain is not coupled with difficulty in understanding intentionality on the part of others (Cheng et al., 2012).

Atypical vmPFC and OFC response to punishment and reward in children with disruptive behaviors and CU traits has also been reported (Finger et al., 2011; Finger et al., 2008). For example, Finger et al. (2008) reported that both typically-developing children and children with ADHD showed a reduction in vmPFC activity following an unexpected punishment. Such reduction in vmPFC activity has been shown to co-occur with prediction error, that is, when an actual outcome differs from the expected outcome (Mitchell 2011). In contrast, youth with disruptive behaviors and CU traits did not show this reduction in vmPFC activity. In another study that used a passive avoidance task in which participants had to learn which stimuli were 'good' (rewarded) and which were 'bad' (unrewarded), Finger et al. (2011) found that children with disruptive behaviors and CU traits showed less OFC and caudate responsiveness to early stimulus-reinforcement exposure, and less OFC responsiveness to rewards. These neural differences can be interpreted as reflecting compromised sensitivity to early reinforcement information in the vmPFC/OFC and caudate, 
and compromised sensitivity to reward outcome information in the vmPFC/OFC, in adolescents with disruptive behaviors and CU traits. Subsequent work, however, suggests that the difficulties in reinforcement learning may not be unique to disruptive behaviors with CU traits, but may instead be a common problem among children with disruptive behaviors as a whole (White et al., 2013; 2014) and relate to the levels of conduct disorder symptoms (White et al., 2016).

Collectively, these functional neuroimaging findings are largely in line with those typically reported in studies of psychopathic adults suggesting that assessing disruptive behaviours and $\mathrm{CU}$ traits identifies children who present with similar risk markers to those seen in adults with psychopathy (e.g., Birbaumer et al., 2005; Kiehl et al., 2001; for a comprehensive review, see Seara-Cardoso \& Viding, 2014). These findings also suggest functional neural bases for why these children respond less to other people's distress and often make and repeat disadvantageous decisions. What is not clear from the current (crosssectional) evidence base is the degree to which neurocognitive biases associated psychopathic features in children can change. Is amelioration in neurocognitive differences associated with behavioural improvement in some children? Or do these children achieve behavioural improvement via other, compensatory mechanisms? Answering questions like this will also constrain how 'biomarkers' such as neuroimaging data may be used. Neuroimaging 'biomarkers' may be primarily useful in informing how treatments might be best constrained (i.e. should you try to recalibrate affective processing or should you deploy approaches that focus on compensatory mechanisms) or they may, in some cases, provide additional risk prediction. Longitudinal data are required to answer these questions.

\section{Findings from genetically informative studies}


In interpreting findings from genetic/epigenetic studies, it is of critical importance to keep in mind that there are no genes that directly give rise to the development of psychopathy. Genes code for proteins that influence characteristics such as neurocognitive vulnerabilities that may in turn increase risk for developing psychopathic features. The neurocognitive vulnerabilities associated with disruptive behaviors that occur together with $\mathrm{CU}$ traits are at least partially distinct from those associated with disruptive behaviors more broadly (see section on neurocognitive findings). This suggests that the risk alleles for psychopathy may be in part independent from risk alleles for disruptive behaviors more broadly. Although an individual's genome likely limits a 'range for phenotypic expression', it does not pre-specify how an individual will turn out. The specific developmental trajectory of any individual is determined by a complex interplay between genetic propensities and other factors that constrain how those genetic propensities are expressed at several different levels of analysis. Genetic variants that are implicated as risk genes for psychopathic presentation may include several genes that confer advantages, as well as disadvantages, depending on the environmental context. It is also of critical importance to remember that an individual's genetic predisposition influences the types of environments the individual will encounter, a phenomenon known as gene-environment correlation (rGE). For example, an individual's genetic predisposition may influence behaviours that will in turn evoke different reactions in others. In order to understand how environmental risk operates in relation to the development of psychopathy, it is therefore important to conduct research into environmental risk within genetically informative study designs.

Here we review genetically informative findings in relation to $\mathrm{CU}$ traits, with particular emphasis on findings in the context of disruptive behaviours. This is to allow comparability with the neurocognitive literature of developmental risk for psychopathy that has primarily focused on differentiating children with disruptive behaviour on CU traits. 
Individual differences in $\mathrm{CU}$ are typically estimated to be moderately to strongly heritable using the standard twin design, which compares resemblance in monozygotic (MZ) twins and dizygotic (DZ) twins, in community samples of children and adolescents (range of heritability estimates $=.45-.72$; see Viding \& McCrory, 2012; Ficks et al., 2014; Flom \& Saudino, 2016; see also Tuvblad et al., 2017 for a recent study with a lower heritability estimate of .25 in 5-year old twins). It is also of interest to note that disruptive behaviors accompanied by high levels of CU traits appear strongly heritable, whereas disruptive behaviors accompanied by low levels of CU traits appear to be more strongly influenced by environmental factors (Viding et al., 2005; 2008).

Twin studies suggest that there is considerable overlap in the genes that influence CU traits and conduct/externalizing problems, but that there are also unique genetic influences on CU (Bezdjian et al., 2011; Forsman et al., 2008; Viding et al., 2007). This finding is consistent with evidence indicating that high levels of CU can occur in the absence of clinical levels of disruptive behaviors (Frick et al., 2003; Kumsta et al., 2012), although this is rare. Persistent high levels of CU typically occur in the presence of disruptive behaviors (Fontaine et al., 2011). Twin research findings also suggest that observed stability in CU/psychopathic traits is largely driven by genetic influences (Flom \& Saudino, 2016; Fontaine et al., 2010; Forsman et al., 2008).

Only a handful of candidate gene-association studies to date have focused on CU traits in children or adolescents with most of these studies focusing on samples with some disruptive behaviour. These studies have tentatively implicated variants of genes related to the serotonin and oxytocin systems (e.g., Beichtman et al., 2012; Dadds et al., 2013; Fowler et al., 2009; Malik et al., 2012; Moul et al., 2013). Findings from these candidate gene studies need to be investigated in larger samples to evaluate whether they reflect true replicable 
associations; however, selecting candidate genes is not straightforward and can lead to unadjusted multiple testing. Because genetic risk may in many cases only 'penetrate' in the presence of environmental risk, genetic studies should carefully document the environmental risk factors in their samples to increase interpretability of the findings, and thereby enhance our understanding of how genetic risk translates to disorder outcomes. For example, one interesting study reported that the long allele of a serotonin transporter polymorphism, found to be related to low amygdala reactivity in prior research, was only a risk genotype for elevated CU traits in the context of lower SES backgrounds (Sadeh et al., 2010). This finding suggests that the degree to which genetic vulnerability to $\mathrm{CU}$ traits is expressed is dependent on the degree to which a child is exposed to environmental disadvantage. However, further studies are required to also investigate the significance of this finding in relation to developing psychopathy in adulthood.

The association studies highlighted above have only considered a limited number of candidate genes. However, an increasing number of genome-wide association (GWA) studies are now being published in the field of psychiatric genetics. These studies systematically scan the genome with hundreds of thousands of DNA markers, made possible by DNA arrays. GWA studies for psychiatric phenotypes have shown that genome-wide "hits" are often in genes not previously hypothesized to influence the phenotype, or in parts of the genome other than genes themselves (Visscher et al., 2012). GWA studies focusing specifically on CU traits (both alone and in combination with disruptive behaviors) suggest that much larger samples will be needed to detect novel associations with common single nucleotide polymorphisms (SNPs) that account for far less than 1\% of the variance (Viding et al., 2010; 2013). Furthermore, a genome wide complex trait analysis study suggests that most of the genetic variance that is important for explaining genetically driven individual differences in $\mathrm{CU}$ traits or disruptive behaviours is not due to the additive effects of common genetic 
variants (Trzaskowski et al., 2013). This means that the search for genetic influences on psychopathy is likely to be complicated by the presence of gene-gene interactions and rare variants, as well as gene-environment interplay. As such, it is questionable how reliable the associations found for individual candidate genes will prove to be. Methods to identify genegene and gene-environment interactions are required, as is whole-genome sequencing to detect rare variants that might contribute to heritability of psychopathic presentation, but which would not be detected by candidate gene or GWAS methods. It may be possible to use information from such studies to indicate the most appropriate preventative approaches in the future, as well as inform how genetic features may constrain environmental inputs. Research into genetic contributions to psychopathic features, including studies using novel epigenetic approaches that may also help uncover mechanisms of gene-environment interplay, is likely to progress greatly in the coming decade. For example, two recent epigenetic studies have found that higher CU traits are associated with greater methylation of the oxytocin receptor gene (Dadds et al., 2014; Cecil et al., 2014), although it remains unclear whether this methylation pattern indexes environmentally- or genetically-driven epigenetic processes.

Harsh and negative parenting has been associated with higher levels of CU traits and disruptive behaviours, while a warm parental style has been associated with lower levels of CU traits and disruptive behaviours in children (for a review, see Waller et al., 2013), but it is not self-evident that such parenting correlates reflect purely environmental causal influences of parenting on behavioral development. Parents with genetic risk factors for psychopathy/antisocial behaviour are likely to display parenting behaviors in line with these risks (e.g. harsh parenting) and may also pass on some risk genes to their offspring, which can increase the chance of developing disruptive behaviours and lack of empathy. This means that part of the association between less harsh parenting and $\mathrm{CU}$ traits/disruptive behaviours may represent a genetic confound (an example of passive gene-environment correlation). We 
also know that children with psychopathic features are extremely challenging to parent. Given that they typically show diminished empathy for others, less remorse, a tendency to manipulate others, self serving behaviours, impulsivity, and little interest in seeking the approval of adults it is not difficult to imagine how such children might be more challenging to parent. It is therefore likely that they evoke different parenting reactions than less challenging children and research suggests that this is the case (Hawes et al., 2011) (an example of evocative gene-environment correlation).

To date only three genetically-informative longitudinal studies have investigated parenting and development of psychopathic features, all focusing on CU traits (Hyde et al., 2016; Viding et al., 2009; Waller et al., 2016). Results from the first of these studies, capitalizing on a monozygotic-twin differences design, suggest that the association between harsh and negative parenting and higher levels of CU traits in children may, at least in part, reflect genetic vulnerability within families (Viding et al., 2009). This could either reflect a shared genetic vulnerability for poor parenting and CU temperament, or an effect of CU temperament in evoking negative/harsh parenting. Complementing this work, two recent studies using the same adoption cohort found that level of antisocial behavior and fearlessness in the biological mother predicted early CU behaviors in toddlers who had been adopted. However, high levels of adoptive mother positive reinforcement were able to buffer the effects of heritable risk for CU behaviors (Hyde et al., 2016; Waller et al., 2016). These findings are extremely encouraging, although it is important to bear in mind that parents in adoptive families are typically very motivated to undertake the challenges of parenting and are also often relatively well-resourced. By contrast, in biological families, parents of children with CU traits are more likely to have a host of genetic and contextual risk factors (including socio-economic disadvantage), which can pose challenges for promoting 
interventions that seek to increase positive reinforcement behaviors toward the child particularly if that child is challenging.

A few studies to date have also reported an association between CU traits and disorganized attachment in children with disruptive behaviours (Bohlin et al., 2012; Pasalich et al., 2011). However, no genetically-informative longitudinal studies exist that could elucidate the degree to which CU tendencies may drive the development of disorganized attachment in at risk children. Several studies by Dadds and colleagues (Dadds et al., 2011; 2012 ; 2014) suggest that compared with other children with disruptive behaviours, those with high levels of CU traits make less eye contact with their mothers in both free play and directed situations. The mothers of children with high levels of CU traits, on the other hand, do not differ from mothers of non-CU children with disruptive behaviours in the amount of eye contact they attempt with their children. This suggests that children with high CU traits and disruptive behaviours bring a number of challenges to the parent-child relationship, which may influence the formation of attachment style. It will be important to identify within a longitudinal design the features of children with high $\mathrm{CU}$ traits and disruptive behaviours that present a challenge to dyadic interactions, as well as carefully characterise the degree to which these are shared with other children with problematic presentation vs. unique to those at risk for developing psychopathy. Other factors, apart from parenting and parental attachment, are also likely to contribute to the development of the combination of disruptive behaviours and CU traits and warrant mention. These include SES, peer relationships, cognitive ability, and pre- and peri-natal risk factors (Viding \& McCrory, 2015). For example, peer relationships of children with high levels of CU traits are characterized by less stability and greater conflict (Muñoz et al., 2008) and children with high levels of CU traits associate more frequently with delinquent friends (Kimonis et al., 2004). However, the extant evidence base is not able to elucidate the degree to which these associations are causal or 
correlational (e.g. related to the phenomenon of gene-environment correlation). Interestingly, delinquent children with CU traits do not seem to be influenced by their friends' peer delinquency (Kerr et al., 2012); rather, their delinquent behavior appears to strongly influence their friends' delinquency (Kerr et al., 2012).

The current evidence base clearly indicates that both genetic and environmental risk factors contribute to developmental risk for psychopathy. We are at present some way away from identifying the precise genes that represent the genetic risk. The extant data suggest that finding such genes will be complicated by the presence of gene-gene interactions, as well as rare genetic variants. The extant evidence base also indicates that although family environmental factors that are associated with disruptive behaviours and CU traits may in part reflect genetic endowment within families, there is also manifest potential for positive environmental factors - such as warm and positive parenting - to ameliorate the development of psychopathic presentation.

\section{Future Research Needs}

Although substantive progress has been made in our understanding of the neurocognitive functioning of individuals at risk of developing psychopathy, as well as the origins of that risk, there are still a number of important questions to be addressed. First, only a limited range of tasks have been used in neurocognitive research (either experimental or imaging studies), the sample sizes in the extant studies (including our own) have often been modest, and the generalisability of the neurocognitive findings across different groups of people has not been systematically investigated. While the current body of findings contains many conceptual replications, exact replications are rare. There are some seemingly 
conflicting findings and it is not currently clear to what extent these reflect task, trait measurement, or sample differences (see e.g. Hyde et al., 2016; Martin-Key et al., 2016). It is important for future studies to use well-constructed measures that are able to clearly isolate specific affective/cognitive processes of interest, and to study whether the findings hold for both sexes or across cultures or ethnicities. It is also important to systematically investigate the aspects of developmental risk for psychopathy beyond CU traits, for example those neurocognitive factors associated with seemingly impulsive and maladaptive decision making and which have recently been isolated in adults with psychopathy (e.g. Baskin-Sommers et al., 2016; Hosking et al., 2017).

Second, there are no longitudinal studies with neuroimaging measures that shed light on how specific processing biases related to psychopathy risk develop nor how malleable such processing biases might be. We also do not know whether clinical improvement is associated with alterations in the neurocognitive systems associated with risk of psychopathy or whether symptom changes relate to altered neural processing in other brain regions that may reflect 'compensatory' mechanisms.

A related, third point, concerns the lack of longitudinal data on neurocognitive functioning embedded within a rich set of other measures - including genetic and epigenetic data, and data on environmental risk and protective factors. As we have described, the specific developmental trajectory of any individual is determined by a complex interplay between genetic propensities and contextual factors that constrain how those genetic propensities are expressed throughout different developmental stages. Longitudinal work incorporating different levels of analysis would enable researchers to investigate a novel set of questions. For example, it could shed light on how genetic vulnerability might bias affective processing and how such a bias might be further potentiated and canalised given 
certain environmental contingencies or how affective processing biases themselves (in both children and their parents) may shape the environment. There are a number of factors that make conducting this kind of research particularly challenging. We have not yet identified a reasonable set of genes that we can confidently say are associated with risk for development of psychopathy. The best way to probe neurocognitive biases across different ages is also not clear, nor will it be trivial to combine the different levels of analyses from the point of view of securing a sufficient sample size. We also have a poor understanding of how environmental risk operates in relation to the development of psychopathy and which are the most critical factors to focus on at different developmental stages.

Fourth, we need to investigate heterogeneity in the causal processes that may lead to the development of psychopathic features: such features may emerge in different children for different reasons. Originally Cleckley (1976) described individuals with psychopathy as being low in anxiety and studies of children at risk for psychopathy often report low levels of co-occurring anxiety in these children (e.g. Frick et al., 1999). However, we now know that a subgroup of children who present with CU traits and disruptive behaviours (a combination taken as a proxy for risk of developing psychopathy) also present with co-occurring anxiety (Kimonis et al., 2012; Kimonis et al., 2011). It appears that these children are also characterised with more frequent experiences of social and environmental adversity (such as maltreatment) than children with CU traits and disruptive behaviours who present without anxiety. Currently, we do not know the degree to which children exposed to adversity who present with CU, disruptive behaviours and co-morbid anxiety share genetic, neurocognitive, hormonal, and psychophysiological characteristics with children who exhibit CU traits and disruptive behaviours without anxiety. Emerging research suggests that those with comorbid anxiety may look more like maltreated and anxious children in general (i.e., showing over-reactivity to affective stimuli, rather than the under-reactivity that is typical for non- 
anxious high-CU children with disruptive behaviours; Kimonis et al., 2012; 2016; 2017). In other words, it is plausible that there may be both genetically- and environmentally'weighted' pathways to psychopathic presentation, and one epigenetic study is in line with this proposal (Cecil et al., 2014). Future research efforts are needed to systematically investigate the neurocognitive presentation and developmental trajectories of children who present with psychopathic features and high vs. low levels of concurrent anxiety.

\section{Treatment Implications}

While some children present with stable high levels of CU traits and disruptive behaviours, for others these traits either diminish or increase with age (e.g. Burke et al., 2007; Fontaine et al., 2010). Encouragingly from a clinical perspective, even for those children and youth who show stable high CU traits and disruptive behaviours over time, interventions can contribute to reductions in disruptive behaviors (Hawes et al., 2014; Waller et al., 2013; Wilkinson et al., 2015). Parent training interventions delivered in early childhood have also been shown to produce lasting reductions in CU traits (see Hawes et al., 2014), although treatment gains achieved with older children are sometimes more modest (Bjørnebekk $\&$ Kiøbli, 2017). The challenge over the next decade will be to more comprehensively delineate what precisely works for these children and how current intervention and prevention programs can be optimized in ways that improve engagement as well as clinical outcomes.

To optimize existing interventions (as well as engagement) we may need a better understanding of gene-environment correlation processes. Such research has the potential to inform clinical approaches that promote warm and consistent parenting. A child with psychopathic features is more likely to evoke negative parenting responses (as well as a sense 
of parental inadequacy) and will furnish more infrequent occasions for parental praise or reward. This in turn increases the likelihood that the pattern of parent-child interaction becomes largely negative in tone. Furthermore, the biological parents of such a child may themselves share some of the same vulnerabilities that characterize their child and may find it harder to implement more many aspects of typical parenting intervention programmes. Biological families of children with psychopathic features may need additional (or different forms of) clinical support in order to facilitate a shift towards more positive patterns of parent-child interaction. These could include intensive and supported reward token-economy adjuncts and extensive support in increasing warm parent-child interactions (see Armstrong \& Kimonis, 2013 for a promising case study).

In addition, it will be important to examine the degree to which the neurocognitive biases associated with psychopathic features are malleable as this will help inform the development of adjuncts to existing parenting or family focused clinical interventions. If it transpires (for example) that a given bias is not malleable, it may be more fruitful to focus on the development of compensatory processes that can have the effect of normalizing behaviour. Relatedly, we also need to investigate whether there are particularly sensitive developmental periods during which the neurocognitive functioning may be most responsive to intervention. Given that the child's processing of the world around them is likely to impact upon their social interactions, development of treatment adjuncts can also be seen as providing extra scaffolding for a positive parent-child relationship and attenuating geneenvironment correlation processes that might otherwise unfold over development. 


\section{Conclusions}

Despite substantial accumulation of new evidence, we still lack a coherent understanding of how genetic and environmental risk factors shape the development of neuro-cognitive processing biases that increase risk for psychopathy, or how those processing biases themselves may come to shape the individual's environmental exposures over time. Longitudinal research combining multiple levels of analyses is critical to progress the field, but conducting such research will be challenging. It will require systematic development of measures that are able to index the development of specific processing biases from infancy to adulthood, as well identification of age relevant environmental risk factors and their mode of operation. For example, why is reduced face preference during infancy associated with increased likelihood of CU traits in early childhood (Bedford et al., 2015)? Does it, perhaps combined with a genetic predisposition to a fearless temperament, lead to fewer opportunities to observe a caregiver's frightened face after a loud noise or flashing light? Might that, in turn, lead to a less consolidated representation of what arousal state is associated with a frightened facial expression and would that make it harder for a child to empathize with another person's distress? Does regular positive reinforcement by a parent promote prosocial behavior in ways that helps the child integrate socially, attenuating difficulties in empathizing? Currently we do not know, but it will be important to find out. Longitudinal investigations including data from different levels of analyses are either scarce or absent, and we do not currently have good data on how the child's predisposition (variously quantified) contributes to the parent-child or child-peer dynamic over time. Fortunately, a number of research groups are engaged in conducting systematic, innovative research to answer these and other questions. We are confident that we will be able to write a very different, much improved review on the development of psychopathy in ten years time. 


\section{References}

American Psychiatric Association. (2013). Diagnostic and statistical manual of mental disorders $\left(5^{\text {th }}\right.$ ed.)Washington, DC: Author.

Andershed H, Gustafson SB, Kerr M, Stattin H (2002). The usefulness of self- reported psychopathy- like traits in the study of antisocial behaviour among non- referred adolescents. European Journal of Personality 16, 383-402.

Armstrong K, Kimonis ER (2013). Parent-child interaction therapy for the treatment of Asperger's disorder in early childhood: A case study. Clinical Case Studies 12, 60-72.

Baskin-Sommers A, Stuppy-Sullivan AM, Buckholtz JW (2016). Psychopathic individuals exhibit but do not avoid regret during counterfactual decision making. Proceedings of the National Academy of Sciences of the United States of America 113, 14438-14443.

Bedford R, Pickles A, Sharp H, Wright N, Hill J (2015). Reduced face preference in infancy: a developmental precursor to callous-unemotional traits?. Biological Psychiatry 78, 144-150.

Beitchman JH, Zai CC, Muir K, Berall L, Nowrouzi B, Choi E, Kennedy JL (2012). Childhood aggression, callous-unemotional traits and oxytocin genes. European Child \& Adolescent Psychiatry 21, 125-132.

Bezdjian S, Raine A, Baker LA, Lynam DR (2011). Psychopathic personality in children: genetic and environmental contributions. Psychological Medicine 41, 589-600.

Birbaumer N, Veit R, Lotze M, Erb M, Hermann C, Grodd W, Flor H (2005). Deficient fear conditioning in psychopathy: a functional magnetic resonance imaging study. Archives of General Psychiatry 62, 799-805.

Bjørnebekk G, Kjøbli J (2017). Observed callousness as a predictor of treatment outcomes in parent management training. Clinical Child Psychology and Psychiatry 22, 59-73. 
Blair RJR, Leibenluft E, Pine DS (2014). Conduct disorder and callous-unemotional traits in youth. New England Journal of Medicine 371, 2207-2216.

Bohlin G, Eninger L, Brocki KC, Thorell LB (2012). Disorganized attachment and inhibitory capacity: predicting externalizing problem behaviors. Journal of Abnormal Child Psychology 40, 449-458.

Burke JD, Loeber R, Lahey BB (2007). Adolescent conduct disorder and interpersonal callousness as predictors of psychopathy in young adults. Journal of Clinical Child and Adolescent Psychology 36, 334-346.

Cecil CA, Viding E, Barker ED, Guiney J, McCrory EJ (2014). Double disadvantage: The influence of childhood maltreatment and community violence exposure on adolescent mental health. Journal of Child Psychology and Psychiatry 55, 839-48.

Cheng Y, Hung AY, Decety J (2012). Dissociation between affective sharing and emotion understanding in juvenile psychopaths. Development and Psychopathology 24, 623636.

Cleckley H. (1976). The mask of sanity ( $1^{\text {st }}$ ed./5th ed.). St. Louis, MO: Mosby.

Cohn MD, Popma A, van den Brink W, Pape LE, Kindt M, van Domburgh L, Doreleijers TAH., Veltman DJ (2013). Fear conditioning, persistence of disruptive behavior and psychopathic traits: an fMRI study. Translational Psychiatry 3, e319.

Colins OF, Andershed H, Frogner L, Lopez-Romero L, Veen V, Andershed AK (2014). A new measure to assess psychopathic personality in children: The Child Problematic Traits Inventory. Journal of Psychopathology and Behavioral Assessment, 36, 4-21.

Dadds MR, Allen JL, McGregor K, Woolgar M, Viding E and Scott S (2014). Callousunemotional traits in children and mechanisms of impaired eye contact during expressions of love: a treatment target?. Journal of Child Psychology and Psychiatry 55, 71-780. 


\section{Dadds MR, Allen JL, Oliver BR, Faulkner N, Legge K, Moul C, Woolgar M, Scott S}

(2012). Love, eye contact and the developmental origins of empathy v.

psychopathy. The British Journal of Psychiatry 200, 191-196.

Dadds MR, Jambrak J, Pasalich D, Hawes DJ, Brennan J (2011). Impaired attention to the eyes of attachment figures and the developmental origins of psychopathy. Journal of Child Psychology and Psychiatry 52, 238-245.

Dadds MR, Moul C, Cauchi A, Hawes DJ, Brennan J (2013). Replication of a ROBO2 polymorphism associated with conduct problems but not psychopathic tendencies in children. Psychiatric Genetics 23, 251-254.

de Wied M, van Boxtel A, Matthys W, Meeus W (2012). Verbal, facial and autonomic responses to empathy-eliciting film clips by disruptive male adolescents with high versus low callous-unemotional traits. Journal of Abnormal Child Psychology 40, 211-223.

Essau CA, Sasagawa S, Frick PJ (2006). Callous-unemotional traits in a community sample of adolescents. Assessment 13, 454-469.

Ficks CA, Dong L, Waldman ID (2014). Sex differences in the etiology of psychopathic traits in youth. Journal of abnormal psychology 123, 406-411.

Finger EC, Marsh AA, Blair KS, Reid ME, Sims C, Ng P, Pine DS, Blair RJR (2011). Disrupted reinforcement signaling in the orbitofrontal cortex and caudate in youths with conduct disorder or oppositional defiant disorder and a high level of psychopathic traits. American Journal of Psychiatry 168, 152-162.

Finger EC, Marsh AA, Mitchell DG, Reid ME, Sims C, Budhani S, Kosson DS, Chen G, Towbin KE, Leibenluft E, Blair JR (2008). Abnormal ventromedial prefrontal cortex function in children with psychopathic traits during reversal learning. Archives of General Psychiatry 65, 586-594. 
Flom M, Saudino KJ (2016). Callous-unemotional behaviors in early childhood: Genetic and environmental contributions to stability and change. Development and Psychopathology 1-8.

Fontaine NM, McCrory EJ, Boivin M, Moffitt TE, Viding E (2011). Predictors and outcomes of joint trajectories of callous-unemotional traits and conduct problems in childhood. Journal of abnormal psychology 120, 730-742.

Fontaine NM, Rijsdijk FV, McCrory EJ, Viding E (2010). Etiology of different developmental trajectories of callous-unemotional traits. Journal of the American Academy of Child \& Adolescent Psychiatry 49, 656-664.

Forsman M, Lichtenstein P, Andershed H, Larsson H (2008). Genetic effects explain the stability of psychopathic personality from mid-to late adolescence. Journal of Abnormal Psychology 117, 606-617.

Fowler T, Langley K, Rice F, van den Bree MB, Ross K, Wilkinson LS, Owen MJ, O'donovan MC, Thapar A (2009). Psychopathy trait scores in adolescents with childhood ADHD: the contribution of genotypes affecting MAOA, 5HTT and COMT activity. Psychiatric Genetics 19, 312-319.

Frick PJ, Cornell AH, Barry CT, Bodin SD, Dane HE (2003). Callous-unemotional traits and conduct problems in the prediction of conduct problem severity, aggression, and self-report of delinquency. Journal of Abnormal Child Psychology 31, 457-470.

Frick PJ, Hare RD (2001). The antisocial process screening device. Toronto, ON: MultiHealth Systems.

Frick PJ, Lilienfeld SO, Ellis M, Loney B, Silverthorn P (1999). The association between anxiety and psychopathy dimensions in children. Journal of Abnormal Child Psychology 27, 383-392. 
Frick PJ, Ray JV, Thornton LC, Kahn RE (2014). Annual Research Review: A developmental psychopathology approach to understanding callous-unemotional traits in children and adolescents with serious conduct problems. Journal of Child Psychology and Psychiatry 55, 532-548.

Frogner L, Gibson CL, Andershed AK, Andershed H (2016). Childhood psychopathic personality and callous-unemotional traits in the prediction of conduct problems. American Journal of Orthopsychiatry Oct 27, Epub ahead of print.

Hare RD, (2003). Manual for the Revised Psychopathy Checklist (2nd ed.). Toronto, ON: Multi-Health Systems.

Hare RD, Neumann CS (2008). Psychopathy as a clinical and empirical construct. Annual Review of Clinical Psychology 4, 217-246.

Hawes DJ, Dadds MR, Frost AD, Hasking PA (2011). Do childhood callous-unemotional traits drive change in parenting practices? Journal of Clinical Child \& Adolescent Psychology 40, 507-518.

Hawes DJ, Price MJ, Dadds MR (2014). Callous-Unemotional Traits and the Treatment of Conduct Problems in Childhood and Adolescence: A Comprehensive Review. Clinical Child and Family Psychology Review 17, 248-276.

Hodsoll S, Lavie N, Viding E (2014). Emotional attentional capture in children with conduct problems: the role of callous-unemotional traits. Frontiers in Human Neuroscience $\mathbf{8}$, 570.

Hosking JG, Kastman EK, Dorfman HM, Samanez-Larkin GR, Baskin-Sommers A, Kiehl KA, Newman JP, Buckholtz JW (2017). Disrupted prefrontal regulation of striatal subjective value signals in psychopathy. Neuron 95, 221-231. 
Hyde LW, Waller R, Trentacosta CJ, Shaw DS, Neiderhiser JM, Ganiban JM, Reiss D, Leve LD (2016). Heritable and Nonheritable Pathways to Early Callous-Unemotional Behaviors. American Journal of Psychiatry. [Epub ahead of print]

Jones AP, Happé FG, Gilbert F, Burnett S, Viding E (2010). Feeling, caring, knowing: different types of empathy deficit in boys with psychopathic tendencies and autism spectrum disorder. Journal of Child Psychology and Psychiatry 51, 1188-1197.

Jones AP, Riley RD, Williamson PR, Whitehead A (2009). Meta-analysis of individual patient data versus aggregate data from longitudinal clinical trials. Clinical Trials $\mathbf{6}$, $16-27$.

Kerr M, Van Zalk M, Stattin H (2012). Psychopathic traits moderate peer influence on adolescent delinquency. Journal of Child Psychology and Psychiatry 53, 826-835.

Kiehl KA. (2015). The Psychopath Whisperer: The Science of Those Without Conscience. Crown: New York

Kiehl KA, Smith AM, Hare RD, Mendrek A, Forster BB, Brink J, Liddle PF (2001). Limbic abnormalities in affective processing by criminal psychopaths as revealed by functional magnetic resonance imaging. Biological Psychiatry 50, 677-684.

Kimonis ER, Frick PJ, Barry CT (2004). Callous-unemotional traits and delinquent peer affiliation. Journal of Consulting and Clinical Psychology 72, 956-966.

Kimonis ER, Frick PJ, Munoz LC, Aucoin KJ (2008). Callous-unemotional traits and the emotional processing of distress cues in detained boys: Testing the moderating role of aggression, exposure to community violence, and histories of abuse. Development and Psychopathology 20, 569-589.

Kimonis ER, Frick PJ, Cauffman E, Goldweber A, Skeem J (2012). Primary and secondary variants of juvenile psychopathy differ in emotional processing. Development and Psychopathology 24, 1091-1103. 
Kimonis ER, Goulter N, Hawes DJ, Wilbur RR, Groer MW (2017). Neuroendocrine factors distinguish juvenile psychopathy variants. Developmental Psychobiology 59, 161-173.

Kimonis ER, Kennealy PJ, Goulter N (2016). Does the self-report Inventory of CallousUnemotional Traits predict recidivism? Psychological Assessment 28, 1616-1624.

Kimonis ER, Skeem J, Cauffman E, Dmitrieva J (2011). Are secondary variants of ‘juvenile psychopathy’ more reactively violent and less psychosocially mature than primary variants? Law and Human Behavior 35, 381-391.

Kumsta R, Sonuga-Barke E, Rutter M (2012). Adolescent callous-unemotional traits and conduct disorder in adoptees exposed to severe early deprivation. The British Journal of Psychiatry 200, 197-201.

Larsson H, Viding E, Rijsdijk FV, Plomin R (2008). Relationships between parental negativity and childhood antisocial behavior over time: A bidirectional effects model in a longitudinal genetically informative design. Journal of Abnormal Child Psychology 36, 633-645.

Lilienfeld SO, Andrews BP (1996). Development and preliminary validation of a self-report measure of psychopathic personality traits in noncriminal population. Journal of Personality Assessment 66, 488-524.

\section{Lockwood PL, Sebastian CL, McCrory EJ, Hyde ZH, Gu X, De Brito SA, Viding E} (2013). Association of callous traits with reduced neural response to others' pain in children with conduct problems. Current Biology 23, 901-905.

Lozier LM, Cardinale EM, VanMeter JW, Marsh AA (2014). Mediation of the relationship between callous-unemotional traits and proactive aggression by amygdala response to fear among children with conduct problems. JAMA Psychiatry 71, 627636. 
Lynam DR, Caspi A, Moffitt TE, Loeber R, Stouthamer-Loeber M (2007). Longitudinal evidence that psychopathy scores in early adolescence predict adult psychopathy. Journal of Abnormal Psychology 116, 155.

Malik AI, Zai CC, Abu Z, Nowrouzi B, Beitchman JH (2012). The role of oxytocin and oxytocin receptor gene variants in childhood-onset aggression. Genes, Brain and Behavior 11, 545-551.

Marsh AA, Blair RJR (2008). Deficits in facial affect recognition among antisocial populations: a meta-analysis. Neuroscience \& Biobehavioral Reviews 32, 454-465.

Marsh AA, Finger EC, Fowler KA, Adalio CJ, Jurkowitz IT, Schechter JC, Pine DS, Decety J, Blair RJR (2013). Empathic responsiveness in amygdala and anterior cingulate cortex in youths with psychopathic traits. Journal of Child Psychology and Psychiatry 54, 900-910.

Marsh A, Finger E, Mitchell D, Reid M, Sims C, Kosson D, Towbin KE, Leibenluft E, Pine DS, Blair R (2008). Reduced amygdala response to fearful expressions in children and adolescents with callous-unemotional traits and disruptive behavior disorders. American Journal of Psychiatry 165, 712-720.

Marsh AA, Finger EC, Schechter JC, Jurkowitz IT, Reid ME, Blair RJR (2011). Adolescents with psychopathic traits report reductions in physiological responses to fear. Journal of Child Psychology and Psychiatry 52, 834-841.

Martin-Key N, Brown T, Fairchild G (2016). Empathic accuracy in male adolescents with conduct disorder and higher versus lower levels of callous-unemotional traits. Journal of Abnormal Child Psychology, 1-13.

McCrory EJ, Viding E (2015). The theory of latent vulnerability: Reconceptualizing the link between childhood maltreatment and psychiatric disorder. Development and Psychopathology 27, 493-505. 
Michalska KJ, Zeffiro TA, Decety J (2016). Brain response to viewing others being harmed in children with conduct disorder symptoms. Journal of Child Psychology and Psychiatry 57, 510-519.

Mitchell KJ (2011). The miswired brain: making connections from neurodevelopment to psychopathology. BMC Biology 9, 23.

Moul C, Dobson-Stone C, Brennan J, Hawes D, Dadds M (2013). An exploration of the serotonin system in antisocial boys with high levels of callous-unemotional traits. PloS ONE 8, e56619.

Muñoz LC, Kerr M, Besic N (2008). The Peer Relationships of Youths With Psychopathic Personality Traits A Matter of Perspective. Criminal Justice and Behavior 35, 212227.

Pasalich DS, Dadds MR, Hawes DJ, Brennan J (2011). Do callous-unemotional traits moderate the relative importance of parental coercion versus warmth in child conduct problems? An observational study. Journal of Child Psychology and Psychiatry 52, $1308-1315$.

Patrick C J (2010). Operationalizing the triarchic conceptualization of psychopathy: Preliminary description of brief scales for assessment of boldness, meanness, and disinhibition. Unpublished test manual, Florida State University, Tallahassee, Florida. Test retrieved from https://www.phenxtoolkit.org/index.php? pageLink=browse. protocoldetails \&id=121601.

Paulhus DL, Neumann CS, Hare RD (in press). Manual for the Self-Report Psychopathy Scale (4th ed.). Toronto: Multi-Health Systems.

Rogers JC, De Brito SA (2016). Cortical and subcortical gray matter volume in youths with conduct problems: a meta-analysis. JAMA Psychiatry 73, 64-72. 
Sadeh N, Javdani S, Jackson JJ, Reynolds EK, Potenza MN, Gelernter J, Lejuez, CW Verona E (2010). Serotonin transporter gene associations with psychopathic traits in youth vary as a function of socioeconomic resources. Journal of Abnormal Psychology 119, 604-609.

\section{Sakai JT, Dalwani MS, Mikulich-Gilbertson SK, Raymond K, McWilliams S, Tanabe J,} Rojas D, Regner M, Banich MT, Crowley TJ (2017). Imaging Decision about Whether to, or Not to, Benefit Self by Harming Others: Adolescents with Conduct and Substance Problems, with or without Callous-Unemotionality, or Developing Typically. Psychiatry Research: Neuroimaging 263, 103-112.

\section{Schwenck C, Mergenthaler J, Keller K, Zech J, Salehi S, Taurines R, Romanos M, Schecklmann M, Schneider W, Warnke A, Freitag CM (2012). Empathy in children with autism and conduct disorder: Group-specific profiles and developmental aspects. Journal of Child Psychology and Psychiatry 53, 651-659.}

Seara-Cardoso A, Viding E (2014). Functional neuroscience of psychopathic personality in adults. Journal of Personality 83, 723-737.

\section{Sebastian CL, McCrory EJ, Cecil CA, Lockwood PL, De Brito SA, Fontaine N M,} Viding E (2012). Neural responses to affective and cognitive theory of mind in children with conduct problems and varying levels of callous-unemotional traits. Archives of General Psychiatry 69, 814-822.

Sylvers PD, Brennan PA, Lilienfeld SO (2011). Psychopathic traits and preattentive threat processing in children: A novel test of the fearlessness hypothesis. Psychological Science 22, 1280-1287.

Trzaskowski M, Dale PS, Plomin R (2013). No genetic influence for childhood behavior problems from DNA analysis. Journal of American Academy of Child and Adolescent Psychiatry 52, 1048-1056. 
Tuvblad C, Fanti KA, Andershed H, Colins OF, Larsson H (2017). Psychopathic personality traits in 5 year old twins: the importance of genetic and shared environmental influences. European Child \& Adolescent Psychiatry 26, 469-479.

Viding E, Blair RJR, Moffitt TE, Plomin R (2005). Evidence for substantial genetic risk for psychopathy in 7-year-olds. Journal of Child Psychology and Psychiatry 46, 592597.

Viding E, Frick PJ, Plomin R (2007). Aetiology of the relationship between callousunemotional traits and conduct problems in childhood. The British Journal of Psychiatry 190, s33-s38.

Viding E, Hanscombe KB, Curtis CJ, Davis OS, Meaburn EL, Plomin R (2010). In search of genes associated with risk for psychopathic tendencies in children: a twostage genome-wide association study of pooled DNA. Journal of Child Psychology and Psychiatry 51, 780-788.

Viding E, Jones AP, Paul JF, Moffitt TE, Plomin R (2008). Heritability of antisocial behaviour at 9: do callous-unemotional traits matter? Developmental Science 11, 1722.

Viding E, McCrory EJ (2015). Developmental risk for psychopathy. In Thapar A, Pine DS, Leckman JF, Scott S, Snowling MJ, Taylor E (Eds.). Rutter's Child and Adolescent Psychiatry (6th ed.). John Wiley \& Sons.

Viding E, McCrory EJ (2012). Genetic and neurocognitive contributions to the development of psychopathy. Development and Psychopathology 24, 969-983.

Viding E, Price TS, Jaffee SR, Trzaskowski M, Davis OS, Meaburn EL, Haworth CM, Plomin R (2013). Genetics of callous-unemotional behavior in children. PloS ONE 8, e65789. 
Viding E, Sebastian CL, Dadds MR, Lockwood PL, Cecil CA, De Brito SA, McCrory EJ (2012). Amygdala response to preattentive masked fear in children with conduct problems: the role of callous-unemotional traits. American Journal of Psychiatry 169, 1109-1116.

Viding E, Simmonds E, Petrides KV, Frederickson N (2009). The contribution of callousunemotional traits and conduct problems to bullying in early adolescence. Journal of Child Psychology and Psychiatry 50, 471-481.

Visscher PM, Brown MA, McCarthy MI, Yang J (2012). Five years of GWAS discovery. American Journal of Human Genetics 90, 7-24.

Waller R, Dishion TJ, Shaw DS, Gardner F, Wilson MN, Hyde LW (2016). Does early childhood callous-unemotional behavior uniquely predict behavior problems or callous-unemotional behavior in late childhood?. Developmental Psychology 52, 1805-1819.

Waller R, Gardner F, Hyde LW (2013). What are the associations between parenting, callous-unemotional traits, and antisocial behavior in youth? A systematic review of evidence. Clinical Psychology Review 33, 593-608.

White SF, Briggs-Gowan MJ, Voss JL, Petitclerc A, McCarthy KR, Blair RJR, Wakschlag LS (2016). Can the fear recognition deficits associated with callousunemotional traits be identified in early childhood?. Journal of Clinical and Experimental Neuropsychology 38, 672-684.

White SF, Brislin S, Sinclair S, Fowler KA, Pope K, Blair RJR (2013). The relationship between large cavum septum pellucidum and antisocial behavior, callous-unemotional traits and psychopathy in adolescents. Journal of Child Psychology and Psychiatry 54, 575-581 
White SF, Fowler KA, Sinclair S, Schechter JC, Majestic CM, Pine DS, Blair RJ (2014).

Disrupted expected value signaling in youth with disruptive behavior disorders to environmental reinforcers. Journal of American Academy of Child and Adolescent Psychiatry 53, 579-588.

White SF, Marsh AA, Fowler KA, Schechter JC, Adalio C, Pope K, Sinclair S, Pine DS, Blair RJR (2012). Reduced amygdala response in youths with disruptive behavior disorders and psychopathic traits: decreased emotional response versus increased topdown attention to nonemotional features. American Journal of Psychiatry 169, 750758.

White SF, Tyler PM, Erway AK, Botkin ML, Kolli V, Meffert H, Pope K, Blair JR (2016). Dysfunctional representation of expected value is associated with reinforcement-based decision-making deficits in adolescents with conduct problems. Journal of Child Psychology and Psychiatry 57, 938-946.

\section{White SF, Williams WC, Brislin SJ, Sinclair S, Blair KS, Fowler KA, Pine DS, Pope K,} Blair JR (2012). Reduced activity within the dorsal endogenous orienting of attention network to fearful expressions in youth with disruptive behavior disorders and psychopathic traits. Development and Psychopathology 24, 1105-1116.

Wilkinson S, Waller R, Viding E (2015). Practitioner review: involving young people with callous unemotional traits in treatment-does it work? A systematic review. Journal of Child Psychology and Psychiatry 57, 552-565.

Yoder KJ, Lahey BB, Decety J (2016). Callous traits in children with and without conduct problems predict reduced connectivity when viewing harm to others. Scientific Reports 6, 20216. 